\title{
EDUCADORES DE CRECHE: CONCEPÇÕES E PRÁTICAS
}

\author{
Eulina da Rocha Lordelo
}

\section{RESUMO}

Em vista da importância das concepções vigentes na cultura, e mais particularmente entre os agentes responsáveis por organizar e prover o cuidado à criança, na qualidade da experiência da creche, o presente estudo se propôs a investigar concepções e práticas de cuidado entre os trabalhadores de uma creche pública da cidade de Salvador. Um total de 45 trabalhadores ( $90 \%$ da população de funcionários da creche) responderam a um questionário, com perguntas abertas e fechadas, incluindo uma escala de ordem de importância de 10 fatores selecionados como aspectos relevantes para a qualidade da creche; ao mesmo tempo, quatro classes da creche foram observadas em períodos diários de 10 a 15 minutos, cobrindose as principais rotinas da creche, como entrada, brinquedo livre, refeições, banho e atividades programadas. Categorias de atividades do adulto foram elaboradas com base nos comportamentos

Apoio Capes/CNPq/PRPPG - Universidade Federal da Bahia. 
observados e suas freqüências, calculadas por grupo. Escalas de ordenação dos itens avaliados foram construídas para cada grupo, através do cálculo das posições médias encontradas. Os resultados encontrados indicam um modelo de creche - em termos de concepções - que pode ser denominado higienista, em que a creche é vista como um lugar responsável pela guarda $e$ desenvolvimento físico da criança. As concepções inferidas estão, em geral, de acordo com as práticas vigentes, com a prevalência de cuidados físicos e atividades ligadas à fiscalização e controle do comportamento da criança. Atividades pedagógicas apareceram apenas na classe de 4 a 5 anos Jardim) e o nível de interação relacionada ao brinquedo da criança (Contato lúdico e Atividades recreativas) representou menos de $10 \%$ do total das atividades do adulto. Esses resultados são interpretados como indicadores de que a experiência da creche para as crianças expostas a esse modelo pode estar ainda muito distante das necessidades de seu desenvolvimento integral. A reorientação das políticas de creche é vista como indispensável, independentemente da melhoria das condições materiais disponíveis, uma vez que diversas experiências indicadas na literatura vêm apontando efeitos marcantes de mudanças na organização da creche sobre a qualidade da experiência da criança.

\section{ABSTRACT}

Because of the importance of cultural conceptions in the quality of care experience, especially among actors who are responsible for organizing and providing children's care, in the quality of the day care center experience. This study aims to investigate care conceptions and practices among the workers of a public day care center in Salvador. A total of 45 workers ( $90 \%$ of the staff) answered a questionnaire, with opened and closed questions, including an ordination scale about the importance of 10 items. These items were selected because of their relevance to the day care center quality; meanwhile four groups were observed in daily samples of 10 to 15 minutes, spanning the main routines, like entrance, free play, meals, 
bath and planned activities. Categories of adult activities, based on observed behaviors, were defined and their frequencies calculated by groups. Ordination scales about the assessed items were constructed for each group, through calculation of the means rating. The results suggest a model of day care center - in terms of conceptions - that we can entitle a hygienist model. In this conception, the day care center is understood as a place in charge of the custody and physical development of children. The deduced conceptions are, in general, according to current practices, with prevailing body care and activities related to supervision and control of the children's behavior. Pedagogic activities were observed only in 4 to 5 years old group and the interaction level related to children's play (ludic contact and recreation activities) were found in less than $10 \%$ of adults activities. These results show that children's day care center experience demonstrated to this model can be still very far from their needs for integral development. The reorientation of day care center policy is considered as indispensable, independently from the improvement about material condition now available, since many experiences pointed in literature are suggesting strong effects of changes in the organization of day care center quality.

\section{INTRODUÇÃO}

Este trabalho visa confrontar concepções de educadores de creches sobre aspectos do seu trabalho com suas ações no dia-a-dia, descrevendo-as e comparando o relacionamento complexo entre diferentes dimensões do comportamento.

A importância deste problema decorre naturalmente da relevância social da creche para a sociedade, em vista das mudanças históricas na organização das famílias, particularmente no Brasil, em que essa modalidade de atendimento à infância é muito recente (Oliveira e Rossetti-Ferreira, 1986). As creches estão disponíveis para menos de um terço da população na idade determinada, incluindo aí 
a oferta de serviços privados (Rosemberg, 1989), sendo reconhecida como dever do Estado há não mais que dez anos.

Pela reconhecida precariedade dos serviços públicos oferecidos, como apontado por muitos pesquisadores brasileiros, como Campos (1985), Rosemberg (1984), Novelino (1988), Rubiano e RossettiFerreira (1985), Mello (1987) e Lordelo (1995), justificam-se os estudos sobre esse problema como um meio de obter informações que subsidiem a emergência de modelos de atuação e a formulação de políticas educacionais.

De fato, os estudos sobre as creches têm evidenciado a notável variabilidade da experiência para a criança, relacionada às condições de estruturação e funcionamento (Scarr, 1993; Belsky, 1988), de forma a justificar as conclusões de que a creche não é uma experiência uniforme, necessitando,para a avaliação de seus efeitos, de uma especificação da qualidade do serviço, particularmente naqueles aspectos mais relevantes para a criança, a exemplo da atuação do adulto, como indicado pelo estágio de conhecimento atual na área (Rossetti-Ferreira, 1984).

Do ponto de vista teórico, o papel do adulto no desenvolvimento da criança vem sendo destacado, seja nos estudos do apego e suas repercussões sobre modalidades de criação de crianças, seja no plano do desenvolvimento cognitivo, para o qual o adulto parece ter o papel crítico de facilitar o desenvolvimento da criança, respondendo às suas demandas com apoio às suas iniciativas e dispondo desafios para novos e mais elevados níveis de realizações (Papousek e Papousek, 1984; Pederson, Moran, Sitko, Campbell, Ghesquire. e Acton; Freund, 1990).

Aspectos como grau de instrução e treinamento na área têm sido considerados pontos importantes na formulação de políticas e avaliação de efeitos. Um dos mais críticos problemas relacionados com a creche, entretanto, e que vem sendo apontado como um dado 
estruturador das políticas sociais e da sua concretização no dia-a-dia da creche, é o das concepções vigentes sobre o problema, presentes na sociedade de forma difusa e concretizadas nas ações dos atores relevantes para o cuidado da criança pequena.

Diversos estudos realizados no Brasil vêm mostrando que as creches são estigmatizadas como "um mal necessário" para aquelas crianças cujas mães trabalham e não podem cuidar delas. Essa concepção está presente nos vários segmentos sociais relacionados com o problema - pais e mães, políticos, pessoal da creche, incluindo os professores, auxiliares e pessoal administrativo das creches, formadores de opinião, entre outros - não obstante as muitas manifestações de educadores e psicólogos quanto à necessária mudança da concepção de creche e às recentes mudanças nas leis, conferindo à creche um caráter de direito da criança e opção educacional das famílias (Rossetti-Ferreira, Amorim e Vitória, 1994; Rosemberg, 1995, 1996).

O problema adquire especial impacto para a qualidade da experiência da criança quando se considera a sua existência dentro da própria instituição creche. Alguns estudos têm mostrado que as relações entre as famílias e a creche são permeadas por essas concepções, prejudicando a necessária cooperação entre famílias e creche. Por exemplo, Haddad (1987 e 1981) mostrou que as educadoras de creches manifestam uma atitude de menosprezo em relação às famílias, principalmente às mães, vistas como menos competentes e/ou efetivas em assumir suas próprias responsabilidades com seus filhos. Muitas educadoras vêem a si próprias como prestadoras de um favor às mães, fora do alcance de qualquer crítica. As próprias mães convivem com sentimentos de culpa por não poderem, elas próprias, cuidar dos seus filhos e, por conseguinte, não se julgam com direito de cobrar das educadoras melhorias no cuidado à criança ou a adoção de práticas de cuidado mais condizentes com suas próprias concepções e estilos. 
O problema pode ser melhor dimensionado quando se considera que as crenças podem ser poderosos organizadores de ações e decisões, como se pode inferir dos estudos sobre profecias auto-realizadoras (Rosenthal e Jacobson, 1964) e das linhas de pesquisas mais recentes que descrevem os sistemas de crenças parentais e suas interconexões com as práticas de criação de filhos (Goodnow, 1988; Applegate, Burleson e Delia, 1992; Rubin e Mills, 1992; Samerof e Fiese, 1992).

Assim, o presente estudo buscou identificar crenças e atitudes em relação à creche e relacioná-las com as práticas reais dos adultos no desempenho normal de suas funções.

\section{Sujeitos}

\section{MÉTODO}

Os sujeitos são provenientes de uma creche pública de Salvador, da qual 45 funcionários ( $90 \%$ do total) foram entrevistados, sendo 43 mulheres e 2 homens. Desse conjunto, apenas uma pessoa (a diretora) possui nível superior completo; os que possuem o segundo grau completo (basicamente as professoras) representam $18 \%$ do total, enquanto o restante dos trabalhadores tem apenas o primeiro grau, em muitos casos, incompleto. Quatro turmas da creche (berçário, maternalzinho, maternal e jardim I) foram investigadas quanto às tarefas em que os adultos (apenas professoras e auxiliares) se engajavam.

\section{Coleta de dados}

\section{Observação}

As classes foram observadas em dias e horários diferentes, cobrindo as principais rotinas da creche, em sessões agrupadas de 10 minutos cada (mínimo de 13 e máximo de 19 sessões por classe). Foram obtidos, em média, 102 minutos de observação por classe, 
registrados cursivamente, em intervalos de 30 segundos. O observador registrava a atividade dos adultos e os alvos de suas ações, além de verbalizações, expressões faciais e contexto.

\section{Questionário}

Foi utilizado um questionário de oito perguntas (ver anexo), a maioria fechadas, solicitando opiniões sobre aspectos da experiência da creche considerados importantes. O questionário incluiu duas escalas, uma de ordenação dos aspectos mais importantes da creche, denominada escala de prioridades da creche e outra de avaliação daquela creche em particular (apenas os resultados da escala de prioridades da creche são mostrados neste artigo). Os 10 itens componentes dessa escala foram: alimentação, assistência médica, atividades pedagógicas, brinquedos, higiene, material de ensino, nível dos professores e auxiliares, organização, segurança e tratamento carinhoso. Os tópicos a serem avaliados foram formulados utilizando-se a linguagem usualmente empregada pelos trabalhadores de creche, de modo a serem compreendidos facilmente por todos os trabalhadores, independentemente de treinamento pedagógico ou grau de instrução. Todos os respondentes receberam instruções coletivamente e assistência individual para esclarecimentos sobre o modo de responder. Dos entrevistados, seis pessoas não sabiam ler e escrever bem; assim, elas responderam o questionário oralmente e suas respostas foram marcadas pelo entrevistador. Embora reconhecendo essa variação como uma fonte de erro nos dados, julgou-se vantajoso incluir essas pessoas na amostra, pelo fato destas representarem uma parcela importante da população de trabalhadores de creche, ocupada não apenas em trabalhos de limpeza e cozinha, mas, algumas vezes, no cuidado direto às crianças, principalmente às mais jovens. 


\section{Tratamento e análise dos dados}

Foram construídas categorias de comportamentos dos adultos, nas situações de observação, e calculadas as suas freqüências relativas por classe. Essas categorias foram definidas como segue.

1. Cuidado físico - trocar fraldas, dar banho, limpar o nariz, alimentar com colher ou mamadeira, acalentar para dormir, tirar e vestir roupa, cortar unhas e outras tarefas da mesma natureza.

2. Arrumação - arrumar cadeiras, lençóis, roupas, colchões, pastas, varrer, preencher fichas de controle.

3. Atividade pedagógica - distribuir material, explicar tarefas, sugerir soluções, ajudar o desempenho da criança; explicar conceitos.

4. Atividade recreativa - ações de recreação do grupo ou, pelo menos, de um subgrupo de crianças: jogar bola, cantar, bater palmas, roda, etc.

5. Controle - ações de reclamar a respeito de comportamento julgado inadequado, manter a ordem, reprimir, advertir.

6. Fora da sala - ausência da sala, por qualquer motivo conhecido, suposto ou desconhecido.

7. À parte - conversar com outra pessoa que não a criança, arrumar seus próprios pertences, comer (em todos os períodos, com exceção dos horários das refeições e de sono das crianças).

8. Contato físico afetivo - manter criança no colo, consolar, acalentar (cantando ou balançando a criança); exclui as ações de acalentar realizadas enquanto a criança está sendo preparada para dormir.

9. Contato lúdico - mostrar e/ou comentar objetos, brinquedos, ações da criança, oferecer brinquedos. 
10. Outros.

11. Sem atividade - o adulto está presente na sala, mas ocupado em outras atividades, em horários de refeições ou de sono das crianças.

Escores do grau de importância dos itens avaliados foram construídos atribuindo-se pontos (de 1 a 10) conforme a posição escolhida para cada item pelos respondentes, obtendo-se, no final, uma posição média dos itens para toda a população e para grupos formados pela classe (berçário, maternalzinho, maternal e jardim).

\section{RESULTADOS}

A atividade que, isoladamente, ocupa a maior parte do tempo do adulto na creche é a do cuidado físico (26,6\%), incluindo trocar fraldas, dar banho, comida, pentear e limpar, entre outras, conforme mostra a tabela 1. A segunda categoria mais importante é a de controle, que envolve reclamar, punir, dar ordens em situações em que a criança está fazendo algo considerado inadequado, com 19\% de todos os intervalos. De fato, as atividades em que o adulto se engaja na creche sugerem um padrão muito distante do que poderia ser esperado de um parceiro do desenvolvimento:as categorias em que 0 adulto não tem qualquer contato com a criança (arrumação, fora da sala, à parte, sem atividade) somam juntas cerca de $34,7 \%$ do tempo da amostra. Para as interações de natureza mais comunicativa resta um tempo muito menor: cerca de $18 \%$ para a soma das categorias contato físico afetivo, atividade pedagógica, atividade recreativa e contato lúdico. 


\section{TABELA 1: DISTRIBUIÇÕES PERCENTUAIS DE ATIVIDADES DOS ADULTOS, POR GRUPO.}

\begin{tabular}{l|c|c|c|c|c}
\hline & Total & \multicolumn{1}{c}{ Berçário } & \multicolumn{1}{c}{ Maternalzinho } & \multicolumn{1}{c}{ Maternal } & Jardim \\
\hline Cuidado físico & 26,6 & $35,4 \%$ & $30,2 \%$ & $14,8 \%$ & $23,4 \%$ \\
Controle & 15 & $9,0 \%$ & $21,7 \%$ & $15,3 \%$ & $14,7 \%$ \\
Arrumação & 13,4 & $13,1 \%$ & $14,2 \%$ & $16,7 \%$ & $8,0 \%$ \\
Fora da sala & 8,7 & $6,5 \%$ & $5,2 \%$ & $15,3 \%$ & $8,0 \%$ \\
À parte & 8,2 & $9,8 \%$ & $8,4 \%$ & $8,6 \%$ & $4,7 \%$ \\
Contato físico afetivo & 7,5 & $14,8 \%$ & $2,8 \%$ & $6,7 \%$ & $3,3 \%$ \\
Atividade recreativa & 5,8 & $4,1 \%$ & $6,6 \%$ & $8,1 \%$ & $4,0 \%$ \\
Sem atividade & 4,4 & $1,6 \%$ & $0,4 \%$ & $6,7 \%$ & $11,4 \%$ \\
Contato lúdico & 2,8 & $2,4 \%$ & $5,7 \%$ & $1,9 \%$ & $0,7 \%$ \\
Atividade pedagógica & 1,8 & $0,0 \%$ & $0,0 \%$ & $0,0 \%$ & $10,0 \%$ \\
Outros & 5,7 & $2,8 \%$ & $4,7 \%$ & $5,7 \%$ & $11,4 \%$ \\
\hline Total & $\mathbf{1 0 0}$ & $\mathbf{1 0 0 , 0} \%$ & $\mathbf{1 0 0 , 0} \%$ & $\mathbf{1 0 0 , 0} \%$ & $\mathbf{1 0 0 , 0} \%$ \\
\hline Tempo (min.) & 410 & 95 & 160 & 90 & 65 \\
\hline Número de respostas & $\mathbf{8 1 3}$ & $\mathbf{2 4 3}$ & $\mathbf{2 1 2}$ & $\mathbf{2 0 9}$ & $\mathbf{1 4 9}$ \\
\hline
\end{tabular}

Essa distribuição varia um pouco em cada classe, seguindo, provavelmente, as características de status desenvolvi mental da criança. Assim, no berçário, as percentagens de cuidado físico e contato físico afetivo são mais altas do que nas demais classes, enquanto as categorias de controle e sem atividade são mais baixas. Uma descrição do aspecto geral do berçário sugere um ambiente no qual as necessidades imediatas das crianças impõem-se absolutamente sobre quaisquer outras, impelidas que são pelo choro, freqüentemente forte, das crianças. Apesar disso, ainda há um percentual de 9,8\% de intervalos em que o adulto está à parte, uma categoria composta para reunir os momentos em que o adulto está conversando com outro adulto ou comendo lanche.

No maternalzinho, em que as crianças têm entre 18 e 30 meses, aproximadamente, o percentual de cuidado físico declina $(30,2 \%)$ em comparação com o do berçário $(35,4 \%)$, enquanto o de controle aumenta fortemente. De fato, é nessa classe que a categoria 
controle tem a freqüência mais alta (21,7\%). É provável, novamente, que essa distribuição reflita as características etárias da criança: diminuindo a necessidade de troca de fraldas (muitas crianças nessa classe já usam shorts) e aumentando a capacidade de locomoção e alimentação independentes da criança, ao mesmo tempo em que aparecem muitos perigos de quedas e conflitos por objetos entre as crianças, aumentam as intervenções do adulto no sentido de aquietar as crianças, mantendo-as em ordem.

Há pouca diferença entre os grupos na categoria arrumação, com exceção do grupo de jardim, em que essa categoria se reduz substancialmente de freqüência (8,0\%), em comparação com as outras classes, cuja freqüência varia de $13,1 \%$ a $16,7 \%$.

Foram encontradas diferenças marcantes na categoria de contato físico afetivo, bem mais alta entre os adultos do berçário e declinando nas outras classes, embora não linearmente.

Esse padrão de atenção à criança é compatível, pelo menos parcialmente, com as concepções sobre creches inferidas da importância atribuída aos itens avaliados. Como se pode ver na tabela 2, o item higiene é o primeiro colocado em ordem de importância para o conjunto dos trabalhadores da creche e essa posição é apontada por todos os grupos, com exceção das professoras. De modo geral, os itens colocados em posição superior são aqueles mais ligados à chamada visão higienista da creche, que valoriza as necessidades do desenvolvimento físico e de saúde. Os itens menos valorizados são aqueles relacionados com um modelo de creche mais educacional, privilegiando o desenvolvimento psicológico da criança, como material de ensino, brinquedos e atividades educativas.

No entanto, há uma forte exceção a essa convergência entre importância atribuída aos itens e o padrão de atenção dispensado à criança pelo adulto, conforme os dados apresentados na tabela 1 . Trata-se do item tratamento carinhoso, que ocupa a segunda posição 
em importância; há uma discrepância entre essa opinião declarada e os comportamentos reais em que os adultos se engajam. A categoria de contato físico afetivo (tabela 1) ocupa a sexta posição em uma lista de 11 categorias identificadas, enquanto contato lúdico está na nona posição. Uma explicação muito provável para essa discrepância é que a forte desejabilidade social do item tratamento carinhoso seja a responsável pela alta importância que lhe é atribuída, não havendo, entretanto, no modelo de creche adotado implicitamente, qualquer planejamento que concretize essa desejabilidade.

\section{TABELA 2: POSICIONAMENTO MÉDIO DOS ITENS PROPOSTOS POR SETOR ${ }^{1}$ (ORDEM DE IMPORTANCIA).}

\begin{tabular}{lcccccc}
\hline & Posição média & Limpeza & Professora & Auxiliar & Cozinha/Lactário & Administração \\
\hline 1. Higiene & 2,89 & $2,14(1)$ & $4,14(3)$ & $3(1)$ & $1,50(1)$ & $3,10(1)$ \\
2. Tratamento carinhoso & 3,98 & $3,14(2)$ & $4,43(4)$ & $3,35(2)$ & $6(7)$ & $4,60(3)$ \\
3. Assistência médica & 4,64 & $5(4)$ & $5(5)$ & $4,85(4)$ & $3,17(2)$ & $4,60(3)$ \\
4. Organização & 4,69 & $5,14(5)$ & $3,28(1)$ & $4,85(4)$ & $4,50(3)$ & $5,60(5)$ \\
5. Alimentação & 5,00 & $4,57(3)$ & $7(8)$ & $4,20(3)$ & $5,83(6)$ & $5(4)$ \\
6. Segurança & 5,22 & $6,14(6)$ & $6,28(7)$ & $5(5)$ & $5,17(4)$ & $3,40(1)$ \\
7. Nível dos prof. e aux. & 5,36 & $6,57(7)$ & $3,71(2)$ & $5,85(6)$ & $5,50(5)$ & $3,80(2)$ \\
8. Atividades educativas & 6,64 & $6,14(6)$ & $5,43(6)$ & $6,70(8)$ & $7,67(9)$ & $7,60(7)$ \\
9. Material de ensino & 7,18 & $7,28(8)$ & $6,28(7)$ & $7,80(9)$ & $6,17(8)$ & $7(6)$ \\
10. Brinquedos & 8,87 & $8,85(9)$ & $9,43(9)$ & $8,30(7)$ & $9,17(10)$ & $10(8)$ \\
\hline Número de respondentes & 45 & 7 & 7 & 20 & 6 & 5 \\
\hline
\end{tabular}

A comparação dos diferentes grupos da creche mostra um compreensível viés funcional. Como pode ser visto no quadro 1 , as professoras relegam o item higiene à terceira posição, enquanto para os outros grupos esse item foi sempre colocado em primeiro lugar. Os grupos que trabalham na limpeza e as auxiliares de sala citam os itens precisamente na mesma ordem: higiene, tratamento carinhoso e alimentação. Para o pessoal da cozinha e do lactário, o item assistência

Os números entre parênteses ao lado das posições médias de cada setor referemse à posição do item na escala ordinal de 1 a 10, para o grupo. 
médica desloca o tratamento carinhoso das três primeiras posições, extremando a adesão ao modelo higienista de creche. Finalmente, as professoras e os trabalhadores da área administrativa mostram uma ordem mais diferenciada. As primeiras trazem o item organização para o primeiro lugar, seguido de nível de professores e auxiliares e higiene; o pessoal de administração traz o item segurança para a primeira posição, juntamente com higiene.

\section{QUADRO 1: COMPARAÇÃO DOSTRÊS ITENS MAIS IMPORTANTES CONFORME A FUNÇÃO DESEMPENHADA NA CRECHE.}

\begin{tabular}{|l|l|l|l|}
\cline { 2 - 4 } \multicolumn{1}{l|}{} & Primeira posição & \multicolumn{1}{c|}{ Segunda posição } & \multicolumn{1}{c|}{ Terceira posição } \\
\hline Limpeza & Higiene & Tratamento carinhoso & Alimentação \\
\hline Professora & Organização & Nível professores e auxiliares & Higiene \\
\hline Auxiliar & Higiene & Tratamento carinhoso & Alimentação \\
\hline Cozinheira/Lactário & Higiene & Assistência médica & Organização \\
\hline Administração & Higiene/Segurança & Nível professores e auxiliares & $\begin{array}{l}\text { Tratamento carinhoso/ } \\
\text { Assistência médica }\end{array}$ \\
\hline
\end{tabular}

\section{DISCUSSÃO E CONCLUSÕES}

Os resultados aqui apresentados sugerem a prevalência de um modelo higienista de creche, expresso nas rotinas em que os adultos se engajam regularmente no seu dia-a-dia e nas concepções subjacentes às suas avaliações dos aspectos mais importantes da creche. Tanto na teoria quanto na prática a creche é um lugar em que a criança deve ser alimentada, lavada e arrumada; sua saúde deve ser preservada, com a devida assistência médica.

A força desse modelo, em concepções e práticas, não deve ser subestimada, embora os dados sejam oriundos de apenas uma creche. Entretanto, é conveniente assinalar que essa instituição parece ser perfeitamente representativa do que é a experiência de creche para parcelas consideráveis da população infantil que utilizam esse 
serviço. Deve-se ressaltar que a creche é integrante do conjunto das mais de 50 creches da cidade de Salvador, administradas diretamente por órgãos do governo estadual ${ }^{2}$.

De fato, não se trata de apontar descaso do governo com a área, um tópico que requereria uma avaliação criteriosa, que não foi objeto do presente trabalho. A creche em que o estudo foi realizado apresenta boas instalações e é administrada com dedicação e esforço por parte dos seus funcionários, recebendo a devida assistência em termos de alimentos, roupas e outros recursos. O ponto a ser enfatizado é precisamente o modelo do serviço prestado, expresso nas formas pelas quais as rotinas são organizadas e nas interações em que adulto e criança engajam-se.

Além disso, esses resultados são amplamente convergentes com os encontrados em outras regiões do país, especialmente no Estado de São Paulo, onde vários autores têm realizado estudos que atestam a prevalência dessas concepções entre trabalhadores e usuários das creches (Campos, 1985, Rosemberg, 1984, Haddad, 1987).

De fato, o adulto não aparece com um parceiro do desenvolvimento da criança, a não ser como suporte às suas necessidades físicas imediatas, embora a situação de creche não possa ser caracterizada como incompatível com tal função (Lordelo, 1995, 1997). O ambiente coletivo absolutamente não é sinônimo de despersonalização. Mesmo as condições materiais mais precárias das creches públicas não parecem ser impedimento para interações ricas e complexas. Ao contrário, as formas de comunicação mais

Houve significativas mudanças nos órgãos responsáveis pela administração central das creches entre a época em que os dados foram coletados e o momento atual. Embora tais mudanças possam gerar diferenças nas políticas adotadas, acreditamos que elas são menos importantes para a discussão aqui apresentada, que trata mais de modelos construídos e compartilhados socialmente, não apenas pelas autoridades responsáveis, mas principalmente pela comunidade envolvida: trabalhadores, usuários e sociedade 
freqüentes no ambiente de creche são a individual e a articulada várias crianças e um adulto, com tema comum, coordenado pelo adulto (Lordelo, 1997).

Embora o papel do adulto no desenvolvimento da criança nos contextos de criação coletiva venha sendo relativizado, dada a importância da outra criança no processo de desenvolvimento (Carvalho e Beraldo, 1989; Oliveira e Rossetti-Ferreira, 1986), não há evidência empírica nem aporte teórico que sustentem um modelo de atuação em que os adultos tenham contatos com a criança limitados basicamente a vigilância e cuidado físico. Ao contrário, o que esses autores vêm enfatizando é a importância da estruturação do ambiente de forma a facilitar o engajamento das crianças em atividades lúdicas e, freqüentemente, mais estruturadas. Como proposto por Campos de Carvalho (1990) e Rossetti-Ferreira, Amorim e Vitória (1994), em tais ambientes, o adulto teria um papel importante no atendimento a necessidades individuais e, acima de tudo, criando condições para o crescimento da criança, objetivos que requerem intencionalidade, conhecimento, treinamento de pessoal e avaliação constantes.

Desses resultados podem ser derivadas diversas implicações práticas para as políticas de creche. Em consonância com a literatura que atribui às idéias e crenças um importante papel na estruturação de práticas sociais (Goodnow, 1988; Applegate, Burleson e Delia, 1992; Rubin e Mills, 1992; Samerof e Fiese, 1992), os pesquisadores e planejadores da área devem, provavelmente, focalizar os modelos implícitos de creches, como um alvo prioritário na busca de soluções para elevar a qualidade do serviço fornecido à criança. 


\section{REFERÊNCIAS BIBLIOGRÁFICAS}

APPLEGATE, J. L.; BURLESON, B. R.; DELIA, J. G. Reflection-enhancing parenting as an antecedent to children's social-cognitive and communicative development. In: SIGEL, I. E; McGILLICUDDY-DELISI, A. V.; GOODNOW, J. J. (Eds.). Parental Belief Systems, Hillsdale p. 3-40, 1992.

BELSKY, J. The "effects" of infant day care reconsidered. Early Childhood Research Quarterly, n. 3, p. 235-272, 1998.

CAMPOS, M. M. Pré-escola: entre a educação e o assistencialismo. Cadernos de Pesquisa, n. 53, p. 21-24, 1985.

CAMPOS DE CARVALHO,M. I. Arranjo espacial e distribuição de crianças de 2-3 anos pela área de atividades livres em creches. São Paulo, 1990. Tese (Doutorado). Instituto de Psicologia, Universidade de São Paulo.

CARVALHO, A. M. A.; Beraldo, K. E. A. Interação criança-criança: o ressurgimento de uma área de pesquisa e suas perspectivas. Cadernos de Pesquisa, n. 71, p. 55-61, 1989.

FREUND, L. S. Maternal regulation of children's problem-solving behavior and its impact on children's performance. Child Development, v. 61, n. 1, p. 113-126, 1990.

GOODNOW, J. J. Parents' ideas, actions, and feelings: models and methods from developmental and social psychology. Child Development, n. 59, p. 286-320, 1988.

HADDAD, L. A relação creche-família: relato de uma experiência. Cadernos de Pesquisa, n. 60, p. 70-78, 1987.

A creche em busca de identidade. São Paulo: Edições Loyola, 1991.

LORDELO, E. R. Ambiente de desenvolvimento humano: uma reflexão a partir do contexto creche. São Paulo, 1995. Tese (Doutorado). Instituto de Psicologia, Universidade de São Paulo.

- Estratégias de comunicação em situação poliádica de creche. Cadernos de Pesquisa. (no prelo). 
MELLO, A. M. Tempo de mudança na creche da Vila Praia. Cadernos de Pesquisa, n. 60, p. 79-84, 1987.

NOVELINO, A. M. Maternidade: um perfil idealizado. Cadernos de Pesquisa, n. 65 , p. 21-29, 1988.

OLIVEIRA, Z. M. R; ROSSETTI-FERREIRA, M. C. Propostas para o atendimento em creches no município de São Paulo: histórico de uma realidade. Cadernos de Pesquisa, n. 56, p. 39-65, 1986.

PAPOUSEK,H.; PAPOUSEK, M. Learning and cognitive in the everyday life of human infants. In: ROSENBLATT, J. S. (Ed.). Advances in the Study of Behavior, New York, v. 14, p. 127-159, 1984.

PEDERSON, D. et al. Maternal sensitivity and the security of infant-mother attachment: a q-sort study. Child Development, n. 61, p. 1974-1983, 1990.

ROSEMBERG, F. O movimento de mulheres e a abertura política no Brasil. Cadernos de Pesquisa, n. 51, p. 73-79, 1984.

. 0 a 5: desencontro de estatísticas e atendimento. Cadernos de Pesquisa, n. 71, p. 33-48, 1989.

A criação de filhos pequenos: tendências e ambigüidades contemporâneas. In: RIBEIRO, I.; RIBEIRO, A. C.T. (Orgs.). Família em processos contemporâneos: inovações culturais na sociedade brasileira. São Paulo: Loyola, 1995. p. 167-190.

. Educação infantil, classe, raça e gênero. Cadernos de Pesquisa, n. 96, p. 58-65, 1996.

ROSENTHAL, R.; JACOBSON, L. Pygmalion in the classroom: teacher expectation and pupils' intellectual development. New York: Holt, Rinehart and Winston, 1964.

ROSSETTI-FERREIRA, M. C. O apego e as reações da criança à separação da mãe: uma revisão bibliográfica. Cadernos de Pesquisa, n. 48, p. 3-19, 1984.

; AMORIM, K. S.; Vitória, T. A creche enquanto contexto possível de desenvolvimento da criança pequena. Revista Brasileira de Crescimento e Desenvolvimento Humano, v. 4, n. 2, p. 35-40. 
RUBIANO, M. B.; ROSSETTI-FERREIRA, M. C. Avaliação longitudinal do desenvolvimento psicológico em crianças de creche (resumo). In: REUNIÃO ANUAL DE PSICOLOGIA (15: Ribeirão Preto: SBP). Sociedade Brasileira de Psicologia (Org.), p. 119.

RUBIN, K. H.; MILLS, R. S. L. Parents' thoughts about children's socially adaptive and maladaptive behaviors: stability, change and individual differences. In: SIGEI, I. E.; MCGILLICUDDY-DELISI, A. V.; GOODNOW, J. J. (Eds.). Parental Belief Systems, Hillsdale, p. 41-70, 1992.

SAMEROFF, A. J.; FIESE, B. H. Family representations of development. In: SIGEL, I. E.; McGILLICUDDY-DELISI, A. V.; GOODNOW, J. J. (Eds.). Parental belief systems, Hillsdale, p. 347-372, 1992.

SCARR, S.; EISENBERG, M. Child care research: issues, perspectives, and results. Annual Review of Psychology, n. 44, p. 613-644, 1993. 


\section{ANEXO}

Questionário

\section{CRECHE X PESQUISA}

Essa pesquisa foi planejada para se conhecer melhor a opinião dos funcionários da creche sobre o serviço que prestamos, suas qualidades e deficiências e modos de melhorar nosso trabalho, a partir da opinião de todos. Responda todas as questões com atenção e depois de refletir o tempo necessário. Não é preciso colocar o seu nome. O nosso interesse é no pensamento do pessoal como um todo.

A Direção/Dept. ${ }^{\circ}$ de Psicologia da UFBa

Assinale a sua área de trabalho/função na creche
( ) Limpeza
( ) Cozinha/lactário
( ) Auxiliar de sala
( ) Enfermagem
( ) Professora
( ) Administração

1. Vamos dar agora uma lista de aspectos que se pode desejar quando se põe uma criança numa creche. Ordene os itens da lista abaixo por ordem de importância, ou seja, para o mais importante, dê o valor 1, para o segundo mais importante, dê o valor 2 e assim por diante até chegar ao menos importante, ao qual deve ser dado o valor 10 .
( ) assistência médica
( ) nível dos professores e auxiliares
( ) atividades educativas
( ) organização da creche
( ) brinquedos
( ) qualidade da comida
( ) higiene
( ) segurança física da criança
( ) material de ensino
( ) tratamento carinhoso 
2. Se desejar, acrescente outros aspectos que você também considera importantes:

3. Agora, avalie cada um desses aspectos como realmente funcionam aqui na Creche $X$. Dê uma nota de 1 a 10 para cada aspecto. Note bem: agora não é preciso ordenar, todos os aspectos podem receber nota 1 ou 10, conforme sua opinião.

( ) nível dos professores e auxiliares ( ) assistência médica

( ) organização da creche ( ) atividades educativas

( ) qualidade da comida ( ) brinquedos

( ) segurança física da criança ( ) higiene

$\begin{array}{ll}\text { ( ) tratamento carinhoso } & \text { ( ) material de ensino }\end{array}$

4. Liste, de um lado, até cinco atividades do seu trabalho que estão entre as que mais lhe agradam e, do outro, até cinco que estão entre as que menos lhe agradam. Seja franco, responda com sinceridade.

Atividades que me agradam Atividades que não me agradam

5. Na sua opinião, quais as providências que poderiam ser tomadas para melhorar o atendimento à criança da creche? Cite até três providências.

6. Cite, se houver, até cinco dificuldades que prejudicam o seu trabalho no dia a dia da creche.

7. Se desejar, acrescente opiniões, críticas, sugestões ou comentários de qualquer tipo sobre esses temas. 